\title{
Sexual Dysfunction Related to Psychotropic Drugs: A Critical Review - Part I: Antidepressants
}

Authors

Affiliations

\author{
A. La Torre ${ }^{1}$, G. Giupponi ${ }^{2}$, D. Duffy ${ }^{2}$, A. Conca ${ }^{2}$
}

${ }^{1}$ U.O. di Psichiatria, Ospedale di Rovereto, Rovereto (Tn), Italy

${ }^{2}$ Servizio Psichiatrico del Comprensorio Sanitario di Bolzano, Bolzano, Italy
Key words

- antidepressant drugs

sexual dysfunction

- sexual side effects

treatment-emergent sexual dysfunction received $\quad 03.07 .2012$

revised 27.03.2013

accepted 24.04.2013

\section{Bibliography}

DOI http://dx.doi.org/ 10.1055/s-0033-1345205

Published online ahead of print:

4 June 2013

Pharmacopsychiatry 2013;

46: 191-199

(c) Georg Thieme Verlag KG

Stuttgart · New York

ISSN 0176-3679

Correspondence

G. Giupponi

S Maurizio Hospital

Psychiatrie

Via Boehler 4

39100 Bolzano

Italy

Tel.: + 39/0471/909 800

Fax: + 39/0471/909 819

giancarlo.giupponi@asbz.it

\section{Abstract}

$\nabla$

Sexual dysfunction is a potential side effect of antidepressant drugs: this article presents a critical review of the current literature. Although many studies have been published on this subject, only some have used a validated sexual function rating scale and most lacked either a baseline or placebo control or both. In addition, many of the studies on sexual dysfunction associated with antidepressants are limited by other

\section{Introduction}

$\nabla$

In recent years, sexual dysfunction induced by psychopharmacological treatment has been the subject of increased interest. It is not surprising that the majority of studies on sexual dysfunction caused by psychopharmacology relate to antidepressant medication, considering that in the USA major depression is the most common mental disturbance [1]. Numerous studies have shown a relationship between antidepressant medication and sexual dysfunction [2-11]; there are also several publications on possible treatment approaches [12-14].

This review aims to examine the available evidence on sexual dysfunction caused by antidepressant medication and to identify useful strategies that might alleviate this problem.

\section{Methods}

$\nabla$

This study was conducted in 2013 using the paper and electronic library resources of the "Azienda Provinciale per i Servizi Sanitari (APSS)" in Trento, Italy (http://atoz.ebsco.com/Titles/2793, latest access: 18 February 2013). The library has access to a wide range of databases including (DYNAMED, MEDLINE Full Text, CINAHL Plus Full Text), The Cochrane Library, Micromedex healthcare series, BMJ Clinical methodological flaws. However, there is consistent evidence to suggest that antidepressant medication adversely affects one or more of the 3 phases of sexual response (desire, arousal and orgasm). Antidepressants with strong serotonergic properties have the highest rate of sexual side effects. Clinicians must be aware of druginduced sexual dysfunction, since its presence can have important consequences on clinical management and compliance.

Evidence. The full list of available journals can be viewed at http://atoz.ebsco.com/Titles/2793, or at the APSS web site (http://www.apss.tn.it). Studies published between 1982 and February 2013 were included in the review.

A literature search was conducted using the key words "antidepressant drugs", "psychotropic drugs", "sexual dysfunction", "sexual side effects", "treatment-emergent sexual dysfunction". All resulting listed articles were reviewed. The articles analyzed in our review are summarized in $\bullet$ Table 1.

\section{Biology of Sexuality: Mechanism of Action of Antidepressants on Sexual Function \\ $\nabla$}

The principal neuroanatomic areas that control sexual behavior include the medial forebrain bundle, the medial preoptic-anterior region of the hypothalamus and its related limbic-hippocampal structures, and the ventral tegmentum of the midbrain [15].

Human sexual activity is modulated by a number of neurotransmitters and hormones, however, their exact mechanism of action on the 3 phases of the sexual response cycle is poorly understood. Sthal [16] suggests that the neurotransmitters involved in the 3 stages (desire, arousal and 
Table 1 In this review we have analyzed: 48 Reviews, 38 RCTs (Randomized Controlled Trials), 9 Case Control Studies, 23 Open label Studies, 19 Case Report Studies, 20 Other Articles.

\begin{tabular}{lllllll} 
& Reviews: $\mathbf{4 8}$ & RCTs: $\mathbf{3 8}$ & Case controls: $\mathbf{9}$ & Open labels: $\mathbf{2 3}$ & Case reports: $\mathbf{1 9}$ & \multicolumn{1}{c}{ Other articles: $\mathbf{2 0}$} \\
References & {$[145,2,115,3,4,5,15,6$,} & {$[40,87,109,84,74$,} & {$[108,147$,} & {$[88,18,27,96$,} & {$[39,41,79,65$,} & {$[140,138,139$,} \\
& $58,7,100,8,59,106,107$, & $155,110,112,85,122$, & $95,131,86$, & $91,101,36,52$, & $148,69,141$, & $136,30,31$, \\
& $60,61,97,28,57,12,83$, & $123,42,35,129,29$, & $117,99,92$, & $37,116,56,26$, & $126,51,49$, & $146,137,16$, \\
& $70,17,63,89,21,44,13$, & $130,81,43,75,151$, & $134]$ & $102,67,78$, & $80,125,50$, & $24,25,71,9$, \\
& $120,76,22,23,149,64$, & $38,66,45,103,104$, & & $118,90,111$, & $53,68,127$, & $55,33,34,135$, \\
& $19,20,142,143,14,105$, & $98,46,47,114,93$, & & $62,11,82,54$, & $128,119,94]$ & $32,1,73]$ \\
& $72,10,144,121,156,150$, & $124,48,152,113,77$, & & $132]$ & &
\end{tabular}

orgasm) of the human sexual response cycle have different mechanisms of action. In stage 1 (desire), dopamine (DA), melanocortin, testosterone and estrogen exert a positive influence, while prolactin and serotonin (5HT) have negative effects. In stage 2, arousal correlates with erection in men and with genital swelling and lubrification in women. Several neurotransmitters facilitate sexual arousal, including nitric oxide (NO), norepinephrine (NE), melanocortin, testosterone, estrogen, acetylcholine (Ach), and dopamine (DA). As with desire, serotonin has a negative effect. Stage 3 (orgasm), which is associated with ejaculation in men, is inhibited by serotonin and facilitated by norepinephrine; dopamine and nitric oxide may have weak positive influences.

Sex hormones (e.g., estrogen, progesterone, and testosterone) substantially influence the neurotransmitter actions that modulate sexual behaviour [15]. These interactions, which occur at both a central and a peripheral level, account for intricate modulations of desire, sexual arousal, and orgasm.

A functioning hypothalmic-pituitary-gonadal axis (HPA axis) is fundamental in the modulation of sexual activity, however little else is known about the influence of the hypothalamic-pituitary-gonadal axis on female and male sexual function. Other neurotransmitters and hormones that can cause sexual dysfunction are probably involved ( $\bullet$ Table 2 ).

Antidepressant-induced sexual dysfunction is mainly due to a sexual inhibitory action. Sexual problems may involve one or more phases of the sexual response cycle [18-20]. Delayed ejaculation is the most commonly reported sexual dysfunction in the literature, other frequently reported problems include delayed and/or absent orgasm, reduced and/or lack of sexual desire, and reduced and/or absent sexual arousal (erectile dysfunction and insufficient vaginal lubrication) [4,15,21-23].

Enhanced sexual functioning is more rarely reported, and generally tends to be associated with a clinical improvement in depression.

The precise mechanism of action of antidepressant-induced sexual dysfunction remains unclear and a subject of discussion whereby no definitive conclusions have been reached $[17,21]$. The pharmacodynamic actions of the various antidepressants are very different and complex; it is also very likely that multiple receptor systems are involved in the etiology of sexual dysfunction $[16,24,25]$.

Overall, the evidence in the literature indicates that an inhibitory action on sexuality is expressed mainly through the activation of a particular serotonin receptor subtype: $5 \mathrm{HT} 2$ receptors $[17,23,26]$.

Other inhibitory mechanisms of action on sexuality include anticholinergic actions, blockade of noradrenergic receptors $\alpha-1$, antihistaminergic actions, antidopaminergic actions and elevated prolactin $[16,17,23-28]$. An inhibitory action on nitric oxide synthase has also been hypothesized [16,23,29].
Table 2 Psychopharmacological effect of neurotransmitters on the 3 stages (desire, arousal and orgasm) of the human sexual response (from: Boyarsky [15], Keltner [17], Stahl [16]).

\begin{tabular}{|c|c|c|}
\hline Stage 1: DESIRE & Stage 2: AROUSAL & Stage 3: ORGASM \\
\hline dopamine (DA) (+) & dopamine (DA) (+) & serotonin $(5 \mathrm{HT})(-)$ \\
\hline melanocortin $(+)$ & melanocortin $(+)$ & norepinephrine (NE) (+) \\
\hline testosterone $(+)$ & testosterone $(+)$ & dopamine (DA) $(+/-)$ \\
\hline estrogen (+) & estrogen (+) & nitric oxide (NO) (+/-) \\
\hline prolactin (-) & \multicolumn{2}{|l|}{ nitric oxide $(\mathrm{NO})(+)$} \\
\hline serotonin $(5 \mathrm{HT})(-)$ & \multicolumn{2}{|l|}{ acetylcholine $(\mathrm{Ach})(+)$} \\
\hline & \multicolumn{2}{|l|}{ norepinephrine (NE) (+) } \\
\hline & \multicolumn{2}{|l|}{ serotonin $(5 \mathrm{HT})(-)$} \\
\hline \multicolumn{3}{|c|}{ 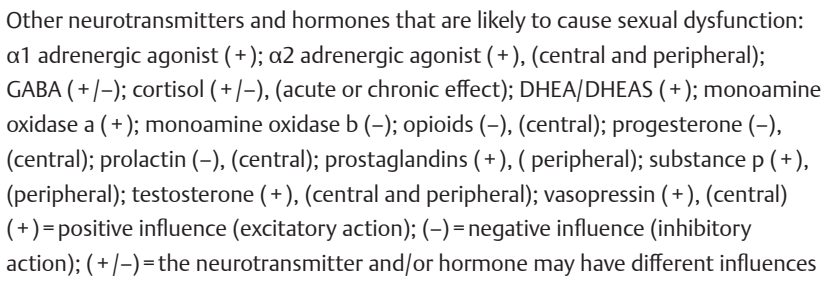 } \\
\hline
\end{tabular}

Some recent evidence also suggests that genetic factors may be involved in the development of sexual dysfunction. Genetic predictors of drug-induced sexual dysfunction-dependent polymorphism of the serotonin 5HT2a receptor [30-34] may exist. Specific genetic polymorphisms of the glutamate gene and variations of the enzyme CYP2D6, may also be involved, but the exact role of this enzyme in sexual dysfunction is unclear.

\section{Antidepressants and Sexual Dysfunction}

$\nabla$

A recent meta-analysis (which included data from studies investigating sexual dysfunction relating to antidepressant treatment that used direct questions or specific questionnaires) showed that the incidence of sexual dysfunction ranged in ascending order, from $4 \%$ for moclobemide and agomelatine, $7 \%$ for amineptine, $8 \%$ for nefazodone, $10 \%$ for bupropion, $24 \%$ for mirtazapine, $26 \%$ for fluvoxamine, $37 \%$ for escitalopram, $42 \%$ for duloxetine and phenelzine, $44 \%$ for imipramine, $70 \%$ for fluoxetine, $71 \%$ for paroxetine, $79 \%$ for citalopram and $80 \%$ for venlafaxine and sertraline ( $\bullet$ Table 3 ). However, it was highlighted that some findings, namely the lower sexual dysfunction found with some SSRIs such as fluvoxamine and escitalopram compared to others, may have been due to the use of scales that are less sensitive than others in assessing the incidence of sexual dysfunction $[19,20]$.

The side-effect profile of antidepressants varies depending on the individual drug. 
Table 3 Percentage of sexual dysfunction reported in the meta-analysis by Serretti and Chiesa [20].

\begin{tabular}{|c|c|c|c|c|c|}
\hline Class & Drug & Percentage & Class & Drug & Percentage \\
\hline \multirow[t]{6}{*}{ SSRI } & citalopram & $79 \%$ & SNRI & venlafaxine & $80 \%$ \\
\hline & escitalopram & $37 \%$ & & duloxetine & $42 \%$ \\
\hline & fluoxetine & $70 \%$ & TCA & amineptine & $7 \%$ \\
\hline & fluvoxamine & $26 \%$ & & imipramine & $44 \%$ \\
\hline & paroxetine & $71 \%$ & MAOI & phenelzine & $42 \%$ \\
\hline & sertraline & $80 \%$ & RIMA & moclobemide & $4 \%$ \\
\hline \multirow[t]{2}{*}{ others } & mirtazapine & $24 \%$ & others & nefazodone & $8 \%$ \\
\hline & bupropion & $10 \%$ & & agomelatine & $4 \%$ \\
\hline
\end{tabular}

\section{(I) Tricyclics}

The early studies on the effects of antidepressant medication on sexual function mainly involved tricyclic antidepressants [3537], of which, clomipramine in particular, but also amitriptyline and imipramine, were found to cause higher rates of sexual dysfunction (decreased libido and lubrication, inhibition of ejaculation and orgasm) [15]. In some studies on clomipramine, rates of sexual dysfunction (especially anorgasmia) were found to be between $41 \%$ and $96 \%$ [38]. In contrast, desipramine and nortriptyline appear to induce lower rates of sexual dysfunction. Clomipramine has also been successfully used in the treatment of patients with premature ejaculation [39-47]. In one study, paroxetine was found to be more effective in delaying ejaculation time [48]. Among the tricyclic antidepressants, amoxapine has been associated with painful [49] and retrograde ejaculation [50]. Spontaneous orgasms and painful ejaculation have been reported with clomipramine [23].

\section{(II) SSRIs}

All SSRIs (selective serotonin reuptake inhibitors: citalopram, escitalopram, fluoxetine, fluvoxamine, paroxetine, sertraline) can cause delayed ejaculation, reduced sexual desire, inhibit or make it difficult to achieve orgasm, and also difficulties in reaching and/ or maintaining an erection. The first reports of sexual dysfunction induced by SSRIs related mostly to fluoxetine [51-54].

The reported rates of sexual dysfunction in men and women taking SSRIs, measured using the Rush sexual inventory, were $60 \%$ and $57 \%$, respectively [55]. However, different rates have been reported in other research. For example, Montejo et al. [56] identified the following rates of SSRI-induced sexual dysfunction: citalopram $72.7 \%$ (48/66 patients), paroxetine $70.7 \%$ (147/208 patients), sertraline $62.9 \%$ (100/159 patients), fluvoxamine $62.3 \%$ (48/77 patients), fluoxetine 57.7\% (161/279 patients). In contrast, Gregorian et al. [57] indicate lower rates of sexual dysfunction, between 30 and $60 \%$, while Clayton et al. [58] report an even lower prevalence of between $36 \%$ and $43 \%$ between the different SSRIs: the same authors maintain that any differences in the sexual side effect profile of SSRIs, are not clinically significant. In support of this, comparative studies of SSRIs have generally not identified any statistical difference in their sexual side effect profile $[10,21,58-62]$ : this finding also seems to be confirmed by the most recent reviews and meta-analyses $[14,19,20,22,63,64]$. Despite such strong evidence, a retrospective study in 2005 (conducted on only 47 patients) [65] seems to suggest an improvement (even more evident after dose reduction) of sexual dysfunction after a switch from some SSRIs (fluoxetine, paroxetine, citalopram, sertraline) and an SNRI (venlafaxine) to escitalopram. The double-blind study of Reimherr et al. [66] demonstrated (in men only) a higher percentage of sexual dysfunction in patients treated with the SSRI sertraline compared to the group treated with the tricyclic antidepressant amitriptyline.

Among the SSRIs, a study on sertraline and paroxetine showed that there was a difference in sexual side effects between men and women: among men, a marked worsening of sexual functioning was reported, whereas in women, there was an improvement in sexual performance, due to an increase in desire and arousal [67]. Isolated cases of increased sexual desire [68], spontaneous orgasms and orgasms during exercise $[23,69]$ have been reported with fluoxetine. Priapism has also been reported with citalopram, while increased desire and anorgasmia have been reported with sertraline [23].

Among the SSRIs, it appears that paroxetine, followed by citalopram and sertraline, are most likely to induce delayed ejaculation. In general, all SSRIs have been proposed as potentially useful in the treatment of premature ejaculation, due to this side effect $[44,70-73]$. Dapoxetine, a new SSRI whose exclusive indication is the treatment of premature ejaculation, has recently been marketed in some European countries [73].

\section{(III) NARI (selective noradrenaline reuptake inhibitor)}

Reboxetine: There is a low rate of reported sexual dysfunction for this antidepressant group [14,74-77]. However, there is insufficient published data in the literature to draw any definitive conclusions.

\section{(IV) Antidepressants with dual action (on both serotonin and norepinephrine)}

Among the antidepressants with dual action (on both serotonin and norepinephrine) we distinguish between:

\section{(a) SNRIs (serotonin and noradrenaline selective reuptake inhibitors)}

Venlafaxine: this drug inhibits orgasm and ejaculation in $12 \%$ of male subjects, therefore less frequently compared to conventional SSRIs, but more frequently compared to nefazodone, trazodone, mirtazapine or bupropion [15]. Kennedy et al. [78] came to similar conclusions, reporting that venlafaxine induced lower rates of sexual dysfunction compared to the SSRIs, but higher rates compared to moclobemide, thus placing it in an intermediate position between these 2 classes of antidepressants: the conclusions of this study must be interpreted with care because some of the statistically significant differences in sexual dysfunction occurred in women but not in men.

Montejo et al. [56] however, reported a high prevalence of side effects: $67.3 \%$ (37/55 patients), a prevalence that increases to $80 \%$ in a recent meta-analysis [19]. In contrast, this prevalence drops to $30 \%$ in research by Clayton et al. [58]. There are reports of increased libido, orgasm and spontaneous erections $[79,80]$. 
Venlafaxine has not been shown to be effective in the treatment of premature ejaculation [81].

Duloxetine: this drug appears to be superior to placebo in delaying ejaculation [82]: similar conclusions were reached by the review by Hirschfeld et al. [83], although the differences (measured using ASEX) between placebo and duloxetine were not significant. A comparison study [84] with escitalopram showed an incidence of sexual dysfunction after 8 weeks of treatment, of $33 \%$ for patients treated with duloxetine and $48.7 \%$ for those treated with escitalopram; however, after 12 weeks of treatment, no significant differences were found between the two patient groups. Delgado et al. found lower rates of sexual dysfunction for duloxetine compared with paroxetine [85]. Also, in the study by Nelson et al. [86], sexual dysfunction caused by duloxetine (46.4\%) was significantly lower than that in the group of patients treated with paroxetine $(61.4 \%)$.

Milnacipran: we did not find any clinical trials specifically designed to determine the sexual side effects of this antidepressant.

\section{(b) NASS (noradrenergic and serotonergic} antidepressant specific)

Mirtazapine: the majority of research indicates a low prevalence of sexual dysfunction [57,87-90]. Labbate [89] reports that although mirtazapine is noted for its tendency to cause less sexual dysfunction than SSRIs, this observation has only been made in non-randomized studies and has not been specifically tested in randomized clinical trials with placebo. In the study by Montejo et al. [56], the reported percentage of sexual dysfunction is $24.4 \%$ (12/49 patients). In the study by Gelenberg et al. [91], there is some weak evidence to suggest that a switch from an SSRI to mirtazapine may improve sexual functioning. However this data must be interpreted with caution, given the small sample size (19 patients) used in this open study. Similar considerations apply to the study by Versiani et al. [92], which found that the sexual side effect profile of mirtazapine was more tolerable than that of fluoxetine. The double-blind study by Wade et al. [93] also indicates less sexual side effects with mirtazapine compared to paroxetine. In an open label pilot study of depressed patients, an increase in sexual functioning was reported, especially in women [88]. The addition of mirtazapine was found to resolve SSRI-induced sexual dysfunction in four patients [94].

(V) NDRI antidepressants (norepinephrine-dopamine reuptake inhibitor), which have both dopaminergic and noradrenergic inhibitory activity

Bupropion: clinical efficacy studies estimate that sexual dysfunction secondary to treatment occurs in less than $3 \%$ of cases [15], while Modell et al. [95] indicate a percentage of $14 \%$. There is some evidence to indicate that bupropion has a positive effect on sexual functioning $[96,97]$, by increasing sexual desire $[98,99]$, which leads to an improvement in psychosexual function [100]. The addition of bupropion during treatment with SSRIs seems to improve sexual side effects [101-105].

Dhillon et al. $[106,107]$ have reported a more tolerable sexual side effect profile for bupropion compared to the SSRIs sertraline, fluoxetine, and escitalopram and compared to the SNRI venlafaxine: similar conclusions were reached by other researchers who compared bupropion with paroxetine $[29,108]$, escita- lopram [109], fluoxetine [110,111], sertraline [112,113] and venlafaxine [114].

(VI) Antidepressants with reversible inhibition of monoamine oxidase activity (RIMA)

Moclobemide: this drug is associated with a low prevalence of sexual dysfunction $[21,78,115,116]$. Philipp et al. [117] have argued that it has sexual enhancing effects, increasing sexual desire in $18 \%$ of patients. In a small open study (conducted on only 5 patients), a switch from fluoxetine to moclobemide led to a resolution of sexual dysfunction [118].

\section{(VII) Antidepressants with irreversible monoamine} oxidase inhibitory activity (MAOI)

Phenelzine, isocarboxazid and tranylcypromine: Sexual dysfunction associated with MAOIs includes reduced sexual desire, erection difficulties, and a reported incidence of between $20 \%$ and $40 \%$ of delayed orgasm and inhibited ejaculation $[2,15,35]$. A case of priapism has been reported following treatment with phenelzine [119]. There have been some reports of ejaculatory dysfunction with phenelzine (delayed ejaculation and failure to ejaculate). Similarly, anorgasmia in females has also been shown to be a common problem with phenelzine; it has also been shown to occur with isocarboxazid and tranylcypromine [120]. In recent years, a transdermal formulation of selegiline (a new monoamine oxidase inhibitor) has been approved in the USA as an antidepressant. Culpepper et al. report that the incidence of patient-rated sexual dysfunction is low and is comparable between selegiline and placebo treatment groups [121].

\section{(VIII) Other antidepressants}

(a) Mixed serotonergic activity (Nefazodone and Trazodone)

Nefazodone: the prevalence of sexual side effects is low (8\%) according to the study by Montejo et al. [56]. In a double-blind comparative study, nefazodone was associated with significantly less sexual dysfunction compared to sertraline [122]. Similar conclusions appear to have been reached by Ferguson et al. [123]. One study found that nefazodone did not delay orgasm or ejaculation, unlike paroxetine and sertraline [124]. A case of spontaneous ejaculation and priapism has been reported [125].

Trazodone: seems to increase sexual desire and prolong time to orgasm [126,127], there has also been some documented cases of priapism [128], a medical emergency. In general, both nefazodone and trazodone are associated with a very low incidence of sexual dysfunction [15].

(b) Melatonergic agonist activity (MT1 and MT2) and to a lesser extent, serotonin 5-HT2C receptor antagonist (agomelatine)

Agomelatine: this drug appears to be associated with very low rates of sexual side effects [129]. In a placebo-controlled study by Kennedy et al. [130], agomelatine was shown to have a lower tendency to cause sexual dysfunction in patients with major depressive disorder compared with venlafaxine, although this difference did not reach statistical significance. In the study by Montejo et al. [131], volunteers who received agomelatine showed a lower rate of sexual dysfunction compared to those taking paroxetine. 
(c) Adenosylmethionine, gepirone, St John's Wort (Hypericum perforatum), tianeptine, vilazodone

An open label study has suggested that switching to tianeptine (a selective serotonin uptake enhancer, with structural similarities to the tricyclic antidepressants) can help to alleviate sexual dysfunction caused by other antidepressants (clomipramine, paroxetine, sertraline and fluoxetine) [132]. In the randomized, double-blind trial of Dording et al. [133], men treated with adjunctive adenosylmethionine had significantly lower erectile dysfunction at endpoint than those treated with adjunctive placebo. We did not find any clinical trials specifically designed to measure sexual side effects induced by adenosylmethionine or St John's Wort (Hypericum perforatum).

Gepirone: this new 5HT1A partial agonist, seems to improve sexual functioning in depressed men [134]. The new antidepressant vilazodone (with both selective serotonin reuptake inhibitor and 5HT1A partial agonist properties) seems to have a low incidence of adverse effects on sexual functioning [135].

\section{Discussion}

$\nabla$

The existing research on sexual dysfunction caused by antidepressive medication is often limited due to epidemiological aspects and methodological flaws of the research.

With regard to antidepressant therapy (especially the SSRIs), the prevalence of sexual dysfunction reported in the literature ranges from as low as $10 \%$ to as high as $80 \%[4,23]$. There are many reasons for the discrepancy in reported prevalence rates, most however are related to methodological research flaws $[4,21]$, some of which include the following:

1. The failure by researchers to adopt a standard definition for sexual dysfunction has been a particular problem, with the result that epidemiological data varies greatly between studies. Also, the definitions used for sexual dysfunction are often unclear or imprecise (e.g., "abnormal ejaculation", "changes in libido").

The classification of sexual dysfunction as proposed by ICD-10 and DSM-IV-TR (both of which receive greatest international consensus) is rarely used. Similar considerations apply for other proposed classifications $[136,137]$. It should be noted that even DSM-IV-TR definitions have been subject to criticism $[138,139]$ and that revised definitions for sexual dysfunction have been suggested for the DSM-V diagnostic criteria [140].

DSM 5 is not due to be published until May 2013, however, the "proposed revision" of "DSM 5 Development" (available online at: http://www.dsm5.org/Pages/Default.aspx, accessed on 10 February 2010) proposes the following new diagnostic categories:

- Sexual interest/arousal disorder in women, which includes previous diagnoses of hypoactive sexual desire disorder (DSM IV code 302.71) and female sexual arousal disorder (DSM IV code 302.72).

- Sexual interest/arousal disorder in men.

- Genito-pelvic pain/penetration disorder, which includes previous diagnoses of vaginismus (not due to a general medical condition) and dyspareunia (not due to a general medical condition).

2. Some researchers have used the term "libido," which unfortunately does not determine which specific phase of the human sexual response is affected by the sexual dysfunction. In fact, the term "libido" is very generic and does not discriminate between the various phases of the sexual response cycle [21]. In this review the authors have tried to avoid the use of the term "libido," retaining it only in cases where it was used in the original publication.

3. Despite a vast amount of literature on the subject, only a small amount of research has intentionally set out to investigate sexual dysfunction caused by antidepressants: in most studies, the prevalence of sexual dysfunction caused by antidepressants was neither considered as a primary or a secondary goal of research. In addition, much of the available data was collected using non standardized or non-uniform methods (controlled clinical trials, post marketing surveys, case reports, etc.) [21]. The identification of sexual dysfunction often relies on the spontaneous disclosure by patients rather than through the use of direct questioning and/or the use of specific rating scales and questionnaires [26,141].

Other methodological limitations need to be carefully considered when interpreting research findings: this applies equally to comparative studies (i.e., studies comparing 2 or more active agents) and non-comparative studies, conducted in mixed populations of patients taking antidepressants for depression or anxiety disorders [21]. Regarding non-comparative studies, in 2002 Montgomery et al. [21], concluded that it is impossible to make reliable comparisons between these studies. They include patients with depression of varying severity, as well as patients with and without anxiety disorders. No two studies have used the same method of assessing sexual dysfunction, which varied from spontaneous descriptions of specific problems, to the use of non-validated questionnaires. In fact, it is still the case that few recent studies have used specific validated rating scales for assessing sexual dysfunction.

4. The various psychometric rating scales (e.g., ASEX: Arizona Sexual Experience Scale; CSFQ: Changes in Sexual Functioning Questionnaire; DSFI: Derogatis Sexual Function Inventory; PRSexDQ: Psychotropic-Related Sexual Dysfunction Questionnaire; RSI: Rush Sexual Inventory; Sex FX: Sex Effect Scale; UKU: Udvalg for Kliniske undersøgelser; etc.) have different sensitivity levels: a recent analysis of the sensitivity of these scales revealed that rates of sexual dysfunction appeared to vary across studies depending on the rating scale used. Some rating scales (e.g., CSFQ) seem to have a greater sensitivity than others. It also appears that the assessment of patients using direct questions rather than specific questionnaires, reduces the ability to correctly diagnose drug-induced sexual dysfunction. Similar considerations appear also to apply to the research on sexual dysfunction induced by anti-psychotic medication $[19,20,142,143]$.

It should be highlighted that relatively few double blind studies have been conducted using any of the above specific rating scales. Although, many studies have been published, only a few used a validated scale for assessing sexual dysfunction and the majority lacked a baseline or placebo control group.

5. In those studies that did not use a specific scale for measuring sexual functioning, the criteria for defining sexual dysfunction or the criteria for attributing it to a specific phase (rather than to another) of the sexual response cycle is often unclear.

6 . The sexual history of patients has not always been systematically explored in the various research projects. Furthermore, a recent published literature review, conducted on 79 clinical trials showed that studies published since 2000 reported a higher percentage $(48.6 \%)$ of drug-induced sexual dysfunction com- 
pared to studies published before the year 2000 (in which the percentage drops to $18 \%$ ) [12].

7. An additional problem is the difficulty in distinguishing and identifying drug-induced sexual effects from the consequences of suffering from a psychiatric disorder, which may in itself have a direct heavy impact on relationships and sexual function [144]: it is important to assess both whether and to what extent, sexual dysfunction represents the expression of an underlying psychiatric disorder. Unfortunately, many studies do not provide data on sexual function prior to the commencement of pharmacological treatment. To understand the relationship between sexual dysfunction and medication, it is necessary to obtain information on baseline sexual functioning (in particular, before the onset of any psychiatric disorder) as well as level of sexual functioning before and after the initiation of any drug treatment. Also, the fact that sexual dysfunction is a common problem in the general population, should not be overlooked [145].

8. Cultural and social factors, such as people's expectations about their level of sexual functioning and their willingness to discuss the subject with a health professional, can vary greatly across different cultures [2]. Many terms used to define sexual dysfunction are subjective and depend on what one considers "normal." Cultural factors, therefore, influence reports on the incidence of sexual dysfunction, which may also vary over time in the same population [21].

9. Recent evidence has shown that doctors tend to underestimate the prevalence of sexual dysfunction in depressed patients $[146,147]$.

Despite these research methodological flaws, there is consistent evidence to suggest that all antidepressants can cause some sexual dysfunction.

\section{Treatment of Antidepressant-Induced Sexual Dysfunction \\ $\nabla$}

A number of treatment approaches have been suggested for the management of sexual dysfunction caused by antidepressants. It is worth highlighting that adding or switching to other medication may be associated with some disadvantages, for example, unwanted side effects (sometime significant) and the inconvenience of having to take additional therapy, which in turn may even lead to reduced or impaired compliance. The treatment strategies, outlined below, should be carefully evaluated on a case by case basis and due consideration should be given to nonpharmacological interventions. It should also be noted that, the evidence to support these strategies is limited, given that few studies used a double-blind study method $[14,60,148-150]$. In addition, studies have sometimes arrived at contrasting conclusions, as in the case of the study by Michelson et al. [151], which demonstrated that neither buspirone nor amantadine were effective in the treatment of sexual dysfunction induced by fluoxetine. Similar conclusions were found by Wheatley [152], who reported no significant differences between Ginkgo biloba and placebo.

Some recommended approaches for the management of sexual dysfunction induced by antidepressants include the following:

1. Wait for a spontaneous reduction of side effects over time.

2. Reduce dose of drug.

3. Arrange a temporary drug reduction or a suspension of drug for 2 days in the week (so-called "therapeutic vacation" or "drug holiday"). This strategy does not apply to fluoxetine, due to its longer half-life.

4. Switch to a different antidepressant drug with fewer sexual side effects, such as bupropion, mirtazapine, or nefazodone.

5. Add a symptomatic therapy [28,151,155-157], including other antidepressants (bupropion, nefazodone or mirtazapine), partial serotonergic agonists and also partial alphanoradrenergic antagonist (buspirone), serotonin antagonist (cyproheptadine), alpha-adrenergic antagonist (yohimbine), dopaminergic agonists (amantadine, lisuride, bromocriptine), psychostimulant dopamine agonists, (methylphenidate and dextroamphetamine), cholinergic enhancers (neostigmine, bethanechol), phosphodiesterase inhibitors (sildenafil, tadalafil, vardenafil) or herbal medicines ("Ginkgo biloba" [152]; "maca root:" Peruvian Ginseng [153]; saffron: "Crocus sativus" [154]). However, among these, the only treatment shown to be of benefit in randomized controlled trials, has been the addition of other antidepressants with a more tolerable sexual side effect profile (such as bupropion or nefazodone) and the addition of phosphodiesterase inhibitors for erectile dysfunction [149].

\section{Sexual Dysfunction Induced by Antidepressants: Conclusions}

Although there is extensive evidence that antidepressants cause sexual dysfunction in both men and women, it is difficult to estimate the exact prevalence. The great variation in methodological approaches makes it extremely difficult to systematically review the literature on the prevalence and incidence of antidepressant-associated dysfunction: it is not surprising that reported rates of sexual dysfunction induced by antidepressants fluctuates widely.

Existing literature confirms that sexual dysfunction is a possible adverse event associated with the use of any antidepressant. However, some studies suggest that antidepressants such as agomelatine, bupropion, mirtazapine, moclobemide and nefazodone are not associated with increased sexual side effects when compared to placebo, even if the data supporting this is only replicated consistently for bupropion $[10,19,20,143]$.

The findings of this review confirm that sexual dysfunction induced by antidepressants is a common problem, with notable associations among patients being treated for depression with SSRIs or SNRIs.

The impact of antidepressant-induced sexual dysfunction negatively affects quality of life [11,62]; has potential implications for patient adherence to medication and the success of antidepressant treatment.

Routine enquiry about sexual dysfunction during clinical interviews at follow-up is essential for drug compliance and disease prognosis.

Various strategies have been proposed to manage sexual dysfunction associated with the use of antidepressants.

\section{Conflict of Interest}

The authors declare no conflicts of interest. 


\section{References}

1 Kessler RC, Berglund P, Demler $O$ et al. The epidemiology of major depressive disorder: results from the National Comorbidity Survey Replication (NCS-R). JAMA 2003; 289: 3095-3105

2 Baldwin DS. Depression and sexual dysfunction. Br Med Bull 2001; 57: 81-99

3 Balon R. Depression, antidepressants, and human sexuality. Prim Psychiatry 2007; 14: 42-44, 47-50

4 Balon R. SSRI-associated sexual dysfunction. Am J Psychiatry 2006; 163: 1504-1509

5 Balon R, Yeragani VK, Pohl $R$ et al. Sexual dysfunction during antidepressant treatment. J Clin Psychiatry 1993; 54: 209-212

6 Clayton AH. Antidepressant-associated sexual dysfunction: a potentially avoidable therapeutic challenge. Prim Psychiatry 2003; 10 : 55-61

7 Cohen S, Kühn KU, Sträter B et al. Adverse side-effect on sexual function caused by psychotropic drugs and psychotropic substances. Nervenarzt 2010; 81: 1129-1139

8 Davidson JRT. Sexual dysfunction and antidepressant. Depression 1995; 2: 233-240

9 Waldinger $M D$, Olivier $B$. Selective serotonin reuptake inhibitorinduced sexual dysfunction: clinical and research considerations. Int Clin Psychoparmacol 1998; 13: S27-S33

10 Werneke $U$, Northey S, Bhugra D. Antidepressant and sexual dysfunction. Acta Psychiatr Scand 2006; 114: 384-397

11 Williams VSL, Edin HM, Hogue SL et al. Prevalence and impact of antidepressant-associated sexual dysfunction in three European countries: replication in a cross-sectional patient survey. J Psychopharmacol 2010; 24: 489-496

12 Haberfellner EM. Strategies for managing antidepressant-induced sexual dysfunction: systematic review of randomised controlled trials. Pharmacopsychiatry 2007; 40: 173-182

13 La Torre A. Impotenze sessuali indotte da psicofarmaci. In: Rifelli G, Rifelli $G$ (eds.). Impotenza maschile, femminile, di coppia. Roma: Scione; 2010; 381-399

14 Taylor MJ. Strategies for managing antidepressant-induced sexual dysfunction: a review. Curr Psychiatry Rep 2006; 8: 431-436

15 Boyarsky BK, Hirschfeld RM. The management of medication-induced sexual dysfunction. Essent Psychopharmacol 2000; 3: 39-58

16 Stahl SM. Stahl's Essential Psychopharmacology: Neuroscientific Basis and Practical Applications. third edition. New York: Cambridge University Press; 2008

17 Keltner NL, McAfee KM, Taylor CL. Mechanisms and treatments of SSRI-induced sexual dysfunction. Perspect Psychiatr Care 2002; 38: 111-116

18 Clayton A, Keller A, McGarvey EL. Burden of phase-specific sexual dysfunction with SSRIs. J Affect Disord 2006; 91: 27-32

19 Serretti A, Chiesa A. Treatment-emergent sexual dysfunction related to antidepressants: a meta-analysis. J Clin Psychoparmacol 2009; 29: 259-266

20 Serretti A, Chiesa A. Antidepressivi e disfunzione sessuale: epidemiologia, meccanismi e strategie di trattamento. Giornale Italiano di Psicopatologia 2010; 16: 104-113

21 Montgomery SA, Baldwin DS, Riley A. Antidepressant medications: a review of the evidence for drug-induced sexual dysfunction. J Affect Disord 2002; 69: 119-140

22 Rosen RC. Prevalence of antidepressant-associated erectile dysfunction. J Clin Psychiatry 2003; 64: 5-10

23 Rosen RC, Lane RM, Menza M. Effects of SSRIs on sexual function: a critical review. J Clin Psychopharmacol 1999; 19: 67-85

24 Sthal SM. The psychopharmacology of sex, Part 1: Neurotransmitters and the 3 phases of the human sexual response. J Clin Psychiatry 2001; 62: 80-81

25 Sthal SM. The psychopharmacology of sex, Part 2: Effects of drugs on the 3 phases of the human sexual response. J Clin Psychiatry 2001; 62: $147-148$

26 Montejo-Gonzales AI, Llorca G, Izquierdo JA et al. SSRI-induced sexual dysfunction: fluoxetine, paroxetine, sertraline, and fluvoxamine in a prospective, multicenter, and descriptive clinical study of 344 patients. J Sex Marital Ther 1997; 23: 176-194

27 Corona G, Ricca V, Bandini E et al. Selective serotonin reuptake inhibitor-induced sexual dysfunction. J Sex Med 2009; 6: 1259-1269

28 Gitlin M. Sexual dysfunction with psychotropic drugs. Expert Opin Pharmacother 2003; 4: 2259-2269

29 Kennedy SH, Fulton KA, Bagby RM et al. Sexual function during bupropion or paroxetine treatment of major depressive disorder. Can J Psychiatry 2006; $51:$ 234-242

30 Ben Zion IZ, Tessler R, Cohen L et al. Polymorphisms in the dopamine D4 receptor gene (DRD4) contribute to individual differences in human sexual behavior: desire, arousal and sexual function. Mol Psychiatry 2006; 11: 782-786

31 Bishop JR, Ellingrod VL, Akroush $M$ et al. The association of serotonin transporter genotypes and selective serotonin reuptake inhibitor (SSRI)-associated sexual side effects: possible relationship to oral contraceptives. Hum Psychopharmacol 2009; 24: 207-215

32 Bishop JR, Moline J, Ellingrod VL et al. Serotonin 2A-1438 G/A and G-Protein Beta 3 subunit C825T polymorphisms in patients with depression and SSRI-associated sexual side effects. Neuropsychopharmacology 2006; 31: 2281-2288

33 Zourková A, Cesková E, Hadasová E et al. Links among paroxetineinduced sexual dysfunctions, gender, and CYP2D6 activity. J Sex Marital Ther 2007; 33: 343-355

34 Zourková A, Hadasová E. Relationship between CYP 2D6 metabolic status and sexual dysfunction in paroxetine treatment. J Sex Marital Ther 2002; 28: 451-461

35 Harrison WM, Rabkin JG, Ehrhardt AA et al. Effects of antidepressant medication on sexual function: a controlled study. J Clin Psychopharmacol 1986; 6: 144-149

36 Hekimian LJ, Freidhoff AJ, Deever E. A comparison of the onset of action and therapeutic efficacy of amoxapine and amitriptyline. J Clin Psychiatry 1978; 39: 633-637

37 Karp JF, Frank E, Ritenour A et al. Imipramine and sexual dysfunction during the long term treatment of recurrent depression. Neuropsychopharmacology 1994; 11: 21-27

38 Monteiro WO, Noshirvani HF, Marks IM et al. Anorgasmia from clomipramine in obsessive-compulsive disorder: a controlled trial. $\mathrm{Br} J$ Psychiatry 1987; 151: 107-112

39 Althof SE. Pharmacological treatment of rapid ejaculation. Psychiatr Clin North Am 1995; 18: 85-94

40 Althof SE, Levine SB, Corty EW et al. A double-bind crossover trial of clomipramine for rapid ejaculation in 15 couples. J Clin Psychiatry 1995; 56: 402-407

41 Althof SE, Resnick K, Levine $S$ et al. Early experience with clomipramine for rapid ejaculation. J Urol 1995; 153: 474A

42 Girgis SM, El-Haggar S, El-Hermouzy S. A double-bind trial of clomipramine in premature ejaculation. Andrologia 1982; 14: 364-368

$43 \mathrm{Kim}$ SC, Seo KK. Efficacy and safety of fluoxetine, sertraline and clomipramine in patients with premature ejaculation: a double-blind placebo controlled study. J Urology 1998; 159: 425-427

44 La Torre A. Il trattamento psicofarmacologico dell'eiaculazione precoce: analisi della letteratura. Rivista di Sessuologia 1999; 23: 379-401

45 Rowland DL, Tai WL, Brummett $K$ et al. Predicting responsiveness to the tretment of rapid ejaculation with $25 \mathrm{mg}$ clomipramine as needed. Int J Impot Res 2004; 16: 354-357

46 Segraves RT, Saran A, Segraves K et al. Clomipramine versus placebo in the treatment of premature ejaculation: a pilot study. J Sex Marital Ther 1993; 19: 198-200

47 Strassberg DS, De Gouveia Brazao CA, Rowland DL et al. Clomipramine in the treatment of rapid (premature) ejaculation. J Sex Marital Ther 1999; 25: 89-101

48 Waldinger MD, Zwindermann AH, Olivier B. On-demand treatment of premature ejaculation with clomipramine and paroxetine: a randomized, double-blind fixed-dose study with stopwatch assessment. Eur Urol 2004; 46: 510-516

49 Kulik FA, Wilbu R. Case report of painful ejaculation as a side effect of amoxapine. Am J Psychiatry 1982; 139: 234-235

50 Noyes R, Garvey MJ, Cook BL et al. Problems with tricyclic antidepressant use in patients with panic disorder or agoraphobia: results of a naturalistic follow-up study. J Clin Psychiatry 1989; 50: 163-169

51 Herman JB, Brotman AW, Pollack MH et al. Fluoxetine-induced sexual dysfunction. J Clin Psychiatry 1990; 51: 25-27

52 Jacobsen FM. Fluoxetine-induced sexual dysfunction and an open trial of yohimbine. J Clin Psychiatry 1992; 53: 119-122

53 Patterson WM. Fluoxetine-induced sexual dysfunction. J Clin Psychiatry 1993; 54: 71

54 Zajecka J, Fawcett J, Schaff $M$ et al. The role of serotonin in sexual dysfunction: fluoxetine-associated orgasm dysfunction. J Clin Psychiatry 1991; 52: 66-68

55 Zajecka J, Mitchell S, Fawcett J. Treatment-emergent changes in sexual function with selective serotonin reuptake inhibitors as measured with the Rush Sexual Inventory. Psychopharmacol Bull 1997; 33: 755-760

56 Montejo AL, Llorca G, Izquierdo JA et al. Incidence of sexual dysfunction associated with antidepressant agents: a prospective multicenter study of 1022 outpatients. J Clin Psychiatry 2001; 62: 10-21

57 Gregorian RS, Golden KA, Bahce A et al. Antidepressant-induced sexual dysfunction. Ann Pharmacother 2002; 36: 1557-1589 
58 Clayton AH, Pradko JF, Croft HA et al. Prevalence of sexual dysfunction among newer antidepressants. J Clin Psychiatry 2002; 63: 357-366

59 Devane CL. Comparative safety and tolerability of selective serotonin reuptake inhibitors. Hum Psychopharmacol 1995; 10: 185-193

60 Fava M, Rankin M. Sexual functioning and SSRIs. J Clin Psychiatry 2002; 63: 13-16

61 Ferguson JM. The effects of antidepressants on sexual functioning in depressed patients: a review. J Clin Psychiatry 2001; 62: 22-34

62 Williams VSL, Baldwin DS, Hogue SL et al. Estimating the prevalence and impact of antidepressant-induced sexual dysfunction in 2 european countries: a cross-sectional patient survey. J Clin Psychiatry 2006; 67: 204-210

63 Kennedy SH, Rizvi S. Sexual dysfunction, depression, and the impact of antidepressants. J Clin Psychopharmacol 2009; 29: 157-164

64 Schweitzer I, Maguire $\mathrm{K}, \mathrm{Ng}$ C. Sexual side-effects of contemporary antidepressants: review. Aust N Z J Psychiatry 2009; 43: 795-808

65 Ashton AK, Mahmood A, Iqbal F. Improvements in SSRI/SNRI-induced sexual dysfunction by switching to escitalopram. J Sex Marital Ther 2005; 31: 257-262

66 Reimherr FW, Chuinard G, Cohn CK et al. Antidepressant efficacy of sertraline: a doubleblind, placebo- and amitriptyline-controlled, multicenter comparison study in outpatients with major depression. J Clin Psychiatry 1990; 51: 18-27

67 Piazza LA, Markowitz JC, Kocsis JH et al. Sexual functioning in chronically depressed patients treated with SSRI antidepressants: a pilot study. Am J Psychiatry 1997; 154: 1757-1759

68 Smith DM, Levitte SS. Association of fluoxetine and return of sexual potency in three elderly man. J Clin Psychiatry 1999; 54: 317-319

69 Benazzi F. Involuntary sperm emission with fluoxetine. Can J Psychiatry 1995; 40: 431

70 Kaplan PM. The use of serotoninergic uptake inhibitors in the treatment of premature ejaculation. J Sex Marital Ther 1994; 20: 321-324

71 Waldinger MD. Lifelong premature ejaculation: from authorithybased to evidence-based medicine. BJU Int 2004; 93: 201-207

72 Waldinger MD, Zwindermann AH, Schweitzer $D H$ et al. Relevance of methodological design for the interpretation of efficacy of drug treatment of premature ejaculation: a systematic review and meta-analysis. Int J Impot Res 2004; 16: 369-381

73 Jannini EA, McMahon CG, Marcel D et al. (eds.). Premature Ejaculation. From Etiology to Diagnosis and Treatment. 2013 SpringerVerlag; Italia

74 Clayton AH, Zajecka J, Ferguson JM et al. Lack of sexual dysfunction with the selective noradrenaline reuptake inhibitor reboxetine during treatment for major depressive disorder. Int Clin Psychopharmacol 2003; 18: 151-156

75 Langworth S, Bodlund O, Agren S. Efficacy and tolerability of reboxetine compared with citalopram. J Clin Psychopharmacol 2006; 26 : 121-127

76 Mucci M. Reboxetine: a review of antidepressant tolerability. J Psychopharmacol 1997; 11: S33-S37

77 Baldwin D, Bridgman K, Buis C. Resolution of sexual dysfunction during double blind treatment of major depression with reboxetine or paroxetine. J Psychopharmacol 2006; 20: 91-96

78 Kennedy SH, Eisfeld BS, Dickens SE et al. Antidepressant-induced sexual dysfunction during treatment with moclobemide, paroxetine, sertraline, and venlafaxine. J Clin Psychiatry 2000; 61: 276-281

79 Altindag A. A case series of increased libido and spontaneous orgasm associated with venlafaxine treatment. Progress Neuropsychopharmacol Biol Psychiatry 2008; 32: 895-896

80 Michael A, Owen A. Venlafaxine-induced increased libido and spontaneous erections. Br J Psychiatry 1997; 170: 193

81 Kilic S, Ergin H, Baydinc YC. Venlafaxine extended release for the treatment of patients with premature ejaculation: a pilot, singleblind, placebo-controlled, fixed-dose crossover study on short-term administration of an antidepressant drug. Int J Androl 2005; 28 : 47-52

82 Zahariou A, Papaioannou P, Karagiannis $G$. The efficacy of duloxetine in the treatment of premature ejaculation. Int Urol Nephrol 2007; 39: 115-118

83 Hirschfeld RM, Vornik LA. Newer antidepressants: review of efficacy and safety of escitalopram and duloxetine. J Clin Psychiatry 2004; 65: 46-52

84 Clayton A, Kornstein S, Prakash A et al. Changes in sexual functioning associated with duloxetine, escitalopram, and placebo in the treatment of patients with major depressive disorder. J Sex Med 2007; 4: 917-929

85 Delgado PL, Brannan SK, Mallinckrodt $\mathrm{CH}$ et al. Sexual functioning assessed in 4 double-blind placebo- and paroxetine-controlled trials of duloxetine for major depressive disorder. J Clin Psychiatry 2005; 66: 686-692

86 Nelson JC, Pritchett YL, Martynorv 0 et al. The safety and tolerability of duloxetine compared with paroxetine and placebo: a pooled analysis of 4 clinical trials. Prim Care Companion J Clin Psychiatry 2006; 8: 212-219

87 Behnke K, Sogaard J, Martin S et al. Mirtazapine orally disintegrating tablet versus sertraline: a prospective onset of action study. J Clin Psychopharmacol 2003; 23: 358-364

88 Boyarsky BK, Haque W, Rouleau MR et al. Sexual functioning in depressed outpatients taking mirtazapine. Depress Anxiety 1999; 9: 175-179

89 Labbate LA. Psychotropics and sexual dysfunction: the evidence and treatments. Adv Psychosom Med 2008; 29: 107-130

90 Saiz-Ruiz J, Montes JM, Ibanez A et al. Assessment of sexual functioning in depressed patients treated with mirtazapine: a naturalistic 6-month study. Hum Psychopharmacol 2005; 20: 435-440

91 Gelenberg AJ, McGahuey C, Laukes C et al. Mirtazapine substitution in SSRI-induced sexual dysfunction. J Clin Psychiatry 2000; 61: 356-369

92 Versiani M, Moreno R, Ramakers-van Moorsel CJA et al. Comparison of the effects of mirtazapine and fluoxetine in severely depressed patients. CNS Drugs 2005; 19: 137-146

93 Wade A, Crawford GM, Angus $M$ et al. A randomised, double-blind, 24-weekstudy comparing the efficacy and tolerability of mirtazepine and paroxetine in depressed patients in primary care. Int Clin Psychopharmacol 2003; 18: 133-141

94 Farah A. Relief of SSRI-induced sexual dysfunction with mirtazapine treatment. J Clin Psychiatry 1999; 60: 260-261

95 Modell JG, Katholi CR, Modell JD et al. Comparative sexual side effects of bupropion, fluoxetine, paroxetine, and sertraline. Clin Pharmacol Ther 1997; 61: 476-487

96 Dobkin RD, Menza M, Marin H et al. Bupropion improves sexual functioning in depressed minority women: an open-label switch study. J Clin Psychopharmacol 2006; 26: 21-26

97 Gardner EA, Johnston JA. Bupropion: an antidepressant without sexual pathophysiological action. J Clin Psychopharmacol 1985; 5: $24-29$

98 Safarinejad MR, Hosseini SY, Asgari MA et al. A randomized, doubleblind, placebo-controlled study of the efficacy and safety of bupropion for treating hypoactive sexual desire disorder in ovulating women. BJU Int 2010; 106: 832-839

99 Segraves RT, Croft H, Kavoussi $R$ et al. Bupropion sustained release (SR) for the treatment of hypoactive sexual desire disorder (HSDD) in non depressed women. J Sex Marital Ther 2001; 27: 303-316

100 Crenshaw TL, Goldberg JP, Stern WC. Pharmacologic modification of psychosexual dysfunction. J Sex Marital Ther 1987; 13: 239-252

101 Gitlin MJ, Suri R, Altshuler L et al. Bupropion-sustained release as a treatment for SSRI-induced sexual side effects. J Sex Marital Ther 2002; 28: 131-138

102 Norden MJ. Buspirone treatment of sexual dysfunction associated with selective serotonin reuptake inhibitors. Depression 1994; 12 : 109-112

103 Safarinejad $M R$. The effects of the adjunctive bupropion on male sexual dysfunction induced by a selective serotonin reuptake inhibitor: a double-blind placebo-controlled and randomized study. BJU Int 2010; 106: 840-847

104 Safarinejad MR. Reversal of SSRI-induced female sexual dysfunction by adjunctive bupropion in menstruating women: a double-blind, placebo-controlled and randomized study. J Psychopharmacol 2011; 25: $370-378$

105 Thase ME, Haight BR, Richard $N$ et al. Remission rates following antidepressant therapy with bupropion or selective serotonin reuptake inhibitors: a meta-analysis of original data from 7 randomized controlled trials. J Clin Psychiatry 2005; 66: 974-981

106 Dhillon S, Yang LP, Curran MP. Spotlight on bupropion in major depressive disorder. CNS Drugs 2008; 22: 613-617

107 Dhillon S, Yang LPH, Curran MP. Bupropion. A review of its use in the management of major depressive disorder. Drugs 2008; 68: 653-689

108 Calandra C, Terranova F, Loiacono P et al. Bupropione nel trattamento del disturbo depressivo maggiore: confronto con paroxetina. Giornale Italiano di Psicopatologia 2010; 16: 128-133

109 Clayton AH, Croft HA, Horrigan JP et al. Bupropion extended release compared with escitalopram: effects on sexual functioning and antidepressant efficacy in 2 randomized, double-blind, placebo-controlled studies. J Clin Psychiatry 2006; 67: 736-746

110 Coleman C, King B, Bolden-Watson C et al. A placebo-controlled comparison of the effects on sexual functioning of bupropion sustained release and fluoxetine. Clin Therapeutics 2001; 23: 1040-1058 
111 Walker PW, Cole JO, Gardner EA et al. Improvement in fluoxetineassociated sexual dysfunction in patients switched to bupropion. J Clin Psychiatry 1993; 54: 459-465

112 Croft H, Settle E, Houser T et al. A placebo-controlled comparison of the antidepressant efficacy and effects on sexual functioning of sustained-release bupropion and sertraline. Clin Ther 1999; 21: 643-658

113 Coleman CC, Cunningham LA, Foster VG et al. Sexual dysfunction associated with the treatment of depression: a placebo-controlled comparison of bupropion sustained release and sertraline treatment. Ann Clin Psychiatry 1999; 11: 205-215

114 Thase ME, Clayton AH, Haight BR et al. A double-blind comparison between bupropion XL and venlafaxine XR. Sexual functioning, antidepressant efficacy and tolerability. J Clin Psychoparmacol 2006; 26: 482-488

115 Baldwin DS. Sexual dysfunction associated with antidepressant drugs. Expert Opin Drug Saf 2004; 3: 457-470

116 Vanderkooy JD, Kennedy SH, Bagby RM. Antidepressant side effects in depression patients treated in a naturalistic setting: a study of bupropion, moclobemide, paroxetine, sertraline, and venlafaxine. Can J Psychiatry 2002; 47: 174-180

117 Philipp M, Kohnen R, Benkert O. A comparison study of moclobemide and doxepin in major depression with special reference to effects on sexual dysfunction. Int Clin Psychopharmacol 1993; 7: 149-153

118 Ramasubbu R. Switching to moclobemide to reverse fluoxetineinduced sexual dysfunction in patients with depression. J Psychiatry Neurosci 1999; 24: 45-50

119 Yeragani VK, Gershon S. Priapism related to phenelzine therapy. N Eng J Med 1987; 317: 117-118

120 Margolese HC, Assalian P. Sexual side effects of antidepressants: a review. J Sex Marital Ther 1996; 22: 209-217

121 Culpepper L, Kovalick LJ. A review of the literature on the selegiline transdermal system: an effective and well-tolerated monoamine oxidase inhibitor for the treatment of depression. Prim Care Companion J Clin Psychiatry 2008; 10: 25-30

122 Feiger A, Kiev A, Shrivastava RK et al. Nefazodone versus sertraline in outpatients with major depression: focus on efficacy, tolerability, and effects on sexual function and satisfaction. J Clin Psychiatry 1996; 57: 53-62

123 Ferguson JM, Shrivastava RK, Stahl SM et al. Reemergence of sexual dysfunction in patients with major depressive disorder: double-blind comparison of nefazodone and sertraline. J Clin Psychiatry 2001; 62: 24-29

124 Waldinger MD, Zwindermann AH, Olivier B. Antidepressants and ejaculation: a double-blind, randomized, placebo-controlled, fixeddose study with paroxetine, sertraline and nafazodone. J Clin Psychopharmacol 2001; 21: 293-297

125 Micheal A, Ramana R. Nefazodone-induced spontaneous ejaculation. Br J Psychiatry 1996; 169: 672-673

126 Gartrell N. Increased libido in women receiving trazodone. Am J Psychiatry 1986; 143 : 781-782

127 Sullivan G. Increased libido in three man treated with trazodone. J Clin Psychiatry 1988; 49: 202-203

128 Warner MD, Peabody CA, Whiteford HA et al. Trazodone and priapism. J Clin Psychiatry 1987; 48: 244-245

129 Kennedy SH. Favorable sexual profile of agomelatine in depressed patients. Eur Neuropsychopharmacol 2006; 16: S 319

130 Kennedy SH, Rizvi S, Fulton K et al. A Double-blind comparison of sexual functioning, antidepressant efficacy and tolerability between agomelatine and venlafaxine XR. J Clin Psychopharmacol 2008; 28: 329-333

131 Montejo AL, Prieto N, Terleira A et al. Better sexual acceptability of agomelatine (25 and $50 \mathrm{mg}$ ) compared with paroxetine $(20 \mathrm{mg})$ in healthy male volunteers. An 8-week, placebo-controlled study using the PRSEXDQ-SALSEX scale. J Psychopharmacol 2010; 1: 111-120

132 Atmaca M, Kuloglu M, Tezcan E et al. Switching to tianeptine in patients with antidepressant induced sexual dysfunction. Hum Psychopharmacol Clin Exp 2003; 18: 277-280

133 Dording CM, Mischoulon D, Shyu I et al. SAMe and sexual functioning. Eur Psychiatry 2012; 27: 391-476

134 Fabre LF, Clayton AH, Smith LC et al. The effect of gepirone-ER in the treatment of sexual dysfunction in depressed men. J Sex Med 2012; 9: $821-829$
135 Clayton AH, Kennedy SH, Edwards JB et al. The effect of vilazodone on sexual function during the treatment of major depressive disorder. J Sex Med 2012, published online: 2012 DEC 6, doi:10.1111/ jsm.12004

136 Basson R, Berman J, Burnett A et al. Report of the international consensus development conference on female sexual dysfunction: definitions and classifications. J Urol 2000; 163: 888-893

137 National Institutes of Health $(\mathrm{NIH})$. NIH Consensus development panel on impotence. JAMA 1993; 270: 83-90

138 Balon $R$. The DSM criteria of sexual dysfunction: need for a change. J Sex Marital Ther 2008; 34: 186-197

139 Balon R, Segraves RT, Clayton A. Issues for DSM-V: sexual dysfunction, disorder, or variation along normal distribution: toward rethinking DSM criteria of sexual dysfunctions. Am J Psychiatry 2007; 164 198-200

140 American Psychiatric Association. DSM 5 Devolepment. Available on line at http://www.dsm5.org/Pages/Default.aspx (latest access on 2010 September 14)

141 Bonierbale $M$, Lançon C, Tignol J. The ELIXIR study: evaluation of sexual dysfunction in 4557 depressed patients in France. Curr Med Res Opin 2003; 19: 114-124

142 Serretti A, Chiesa A. A meta-analysis of sexual dysfunction in psychiatric patients taking antipsychotics. Int Clin Psychopharmacol 2011; 26: $130-140$

143 Serretti A, Chiesa A. Sexual side effects of pharmacological treatment of psychiatric diseases. Clin Pharmacol Ther 2011; 89: 142-147

144 Zemishlany Z, Weizman A. The impact of mental illness on sexual dysfunction. Adv Psychosom Med 2008; 29: 89-106

145 Angst J. Sexual problems in healthy and depressed persons. Int Clin Psychopharmacol 1998; 13: S1-S4

146 Chen KC, Yang YK, Lee IH et al. Sexual dysfunction and physicians perception in medicated patients with major depression in Taiwan. Depress Anxiety 2008; 25: E56-E62

147 Cohen S, Kühn K-U, Bender S et al. Sexual impairment in psychiatric inpatients: focus on depression. Pharmacopsychiatry 2007; 40: 58-63

148 Balon $R$, Segraves RT. Survey of treatment practices for sexual dysfunction(s) associated with anti-depressants. J Sex Marital Ther 2008; 34: 353-365

149 Rudkin L, Taylor MJ, Hawton KKE. Strategies for managing sexual dysfunction induced by antidepressant medication (protocol). The Cochrane Database of Systematic Reviews 2002, Issue 4. Art. No.: CD003382. doi:10.1002/14651858.CD003382

150 Clayton AH, Montejo AL. Major depressive disorder, antidepressants, and sexual dysfunction. J Clin Psychiatry 2006; 67: 33-37

151 Michelson D, Bancroft J, Targum $S$ et al. Female sexual dysfunction associated with antidepressant administration: a randomized, placebo-controlled study of pharmacologic intervention. Am J Psychiatry 2000; 157: 239-243

152 Wheatley $D$. Triple-blind, placebo-controlled trial of Ginkgo biloba in sexual dysfunction due to antidepressant drugs. Hum Psychopharmacol 2004; 19: 545-548

153 Dording CM, Fisher L, Papakostas G et al. A double-blind, randomized pilot dose-finding study of maca root (L.Meyenii) for the management of SSRI-induced sexual dysfunction. CNS Neuroscience Therapeutics 2008; 14: 182-191

154 Modabbernia A, Sohrabi H, Nasehi AA et al. Effect of saffron on fluoxetine-induced sexual impairment in men: randomized double-blind placebo-controlled trial. Psychopharmacology 2012; 223: 381-388

155 Clayton AH, Warnock JK, Kornstein SG et al. A placebo-controlled trial of bupropion SR as an antidote for selective serotonin reuptake inhibitor-induced sexual dysfunction. J Clin Psychiatry 2004; 65: 62-67

156 Baldwin DS, Palazzo MC, Masdrakis VG. Reduced treatment-emergent sexual dysfunction as a potential target in the development of new antidepressants. Depress Res Treat 2013; http://dx.doi.org/ $10.1155 / 2013 / 256841$

157 Zajecka J. Strategies for the treatment of antidepressant-related sexual dysfunction. J Clin Psychiatry 2001; 62: 35-43 